\title{
Research on the Development of New Energy Vehicle Sharing in China Based on the Concept of Green Travel
}

\author{
Anqi $\mathrm{Lv}^{1 *}$, Zhiqiang Zhu², Guohua Cheng ${ }^{2}$, Yi $\mathrm{Jia}^{2}$ and Ling $\mathrm{Shi}^{3}$ \\ ${ }^{1}$ Research Institute of Highway Ministry of Transport / Zhonglu Gongke (Beijing) Investment \& Consulting Co., Ltd., Beijing, 100088, \\ China \\ ${ }^{2}$ Research Institute of Highway Ministry of Transport, Beijing, 100088, China \\ ${ }^{3}$ Research Institute of Highway Ministry of Transport / Zhonglu Gongke (Beijing) Investment \& Consulting Co., Ltd., Beijing, 100088, \\ China
}

\begin{abstract}
As the urbanization in China is accelerating, "urban diseases" such as city congestion and environmental pollution arise. Traffic is one of the important factors leading to such urban problems. Therefore, in order to succeed in pollution prevention and control, overcome the shortcomings in urban traffic, and realize high-quality development of transport service, we should promote the development of green transport based on low carbon and environmental protection, and intensively implement green travel. First of all, we should accelerate the upgrading of transportation equipment technology, speed up the promotion and application of new energy vehicles in the field of car sharing, and promote the green and low-carbon development of transport service. Based on it, this paper first defines the green travel, new energy vehicle sharing and other related concepts, and analyzes the impact of new energy vehicle sharing, and then sorts out the development process of new energy vehicle sharing in China and analyzes the development trend and problems being confronted with in this field, and finally puts forward the development policy suggestions on domestic new energy vehicle sharing.
\end{abstract}

\section{Related concepts and impact analysis}

\section{(I) Related concepts}

\section{Green travel}

Green travel refers to a trip mode guided by the concept of green development, in which energy-saving, low-carbon and environmentally-friendly means of transportation are chosen, considering the harmonious development of people, society and environment. It gives priority to the energy-saving and new energy vehicles with low energy consumption and low pollution, and comprehensively uses big data, cloud computing and mobile Internet technology to meet the travel demand of people. "Internet + " enriches the public experience of green travel, and the "Internet +" sharing service mode, such as on-line car-hailing, Internet rental bicycle and time-sharing rental, has been popularized rapidly, playing a positive role in building green travel system.

\section{New energy vehicle}

The new energy vehicle refers to the vehicle with more advanced new technology, new structure and new principle, which is powered by new energy fuel. Its new power sources mainly include: conventional fuel for the new vehicle power device and new energy fuel with environmental friendliness. According to the different power sources, it can be divided into electric vehicle, hydrogen powered vehicle, hybrid electric vehicle, fuel cell electric vehicle, biofuel vehicle, and other new energy vehicles.

\section{New energy vehicle sharing}

The Guiding Opinions on Promoting the Healthy Development of Minibus Rental jointly issued by the Ministry of Transport and the Ministry of Housing and Urban-Rural Development on August 4, 2017 makes clear that car sharing service is a type of car rental service, and the enterprises of car sharing service should have the business scope of car rental. In addition, it also stresses that car sharing service is a type of minibus rental service and is a vertical segmentation of car rental market in essence.

Currently, the new energy vehicle sharing in China refers to the sharing service of small and micro new energy vehicles (that is time-sharing rental mode), which provides users with on-line self-service car reservation, pickup and return and expense settlement through the network service platform built by Internet and modern information technology. In essence, it is a transformation from "one person, one vehicle" to "multiple people, one vehicle", green, low-carbon, energy-saving and environmentally friendly trip mode.

(II) Analysis on the impact of new energy vehicle sharing

First, the rapid growth of the number of traditional fuel vehicles at present in China has led to the increasingly serious urban congestion and "parking difficulty". With the emergence of new energy vehicle

"Corresponding author's e-mail: 254836782@qq.com 
sharing travel mode, it can largely relieve the traffic pressure, reduce the occupation of parking space, and improve the use rate of vehicles. To a certain extent, it helps to reduce the number of private cars and driving mileage of motor vehicles, guide people to change their travel habits, and gradually transform to public transport and non-motorized transport, so as to reduce traffic flow and air pollution and enhance traffic efficiency.

Second, compared with the high gasoline and maintenance costs of traditional vehicles, new energy sharing vehicles do not need to consider these expenditure, which greatly reduces the travel costs. Generally, the fuel consumption of a car is nearly 7 liters per 100 kilometers, a cost of about 50 yuan, while the electricity consumption of an electric sharing car is 15 degrees per 100 kilometers, a cost of about 15 yuan, which is one third of the cost of a private car. If choosing new energy sharing vehicle, high annual insurance and maintenance costs for private car can be avoided, saving a lot of travel costs.

Third, the sharing of new energy vehicle can directly reduce the emission of harmful gases, relieving the pressure caused by current environmental problems. At present, most of China's new energy sharing vehicles adopt electric new energy vehicles. Electric energy can be supplied through renewable energy technology such as wind power, hydropower and photovoltaic, which really achieves "no pollution and zero emission". In addition, with continuous promotion of new energy vehicle sharing, more and more consumers have full acknowledge of this new energy vehicle as a new means of transportation, playing a demonstrative role in the future popularization of new energy vehicles, so as to drive the continuous innovation and development of the whole new energy vehicle industry and technology.

\section{Development of new energy vehicle sharing in China}
(I) Development process of new energy vehicle sharing in China
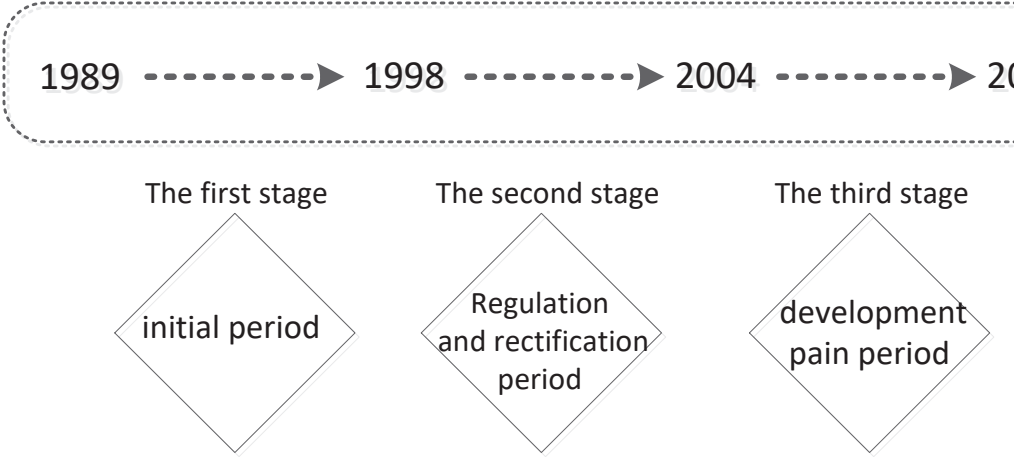

2014

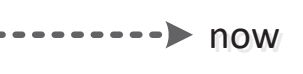

Figure 1. Development process of new energy vehicle sharing in China.

\section{The first stage: initial period (1989-1998)}

The development of car rental industry in China began in Beijing. In 1989, in order to meet the needs of foreign journalists and related people for the convenience, mobility and privacy of transportation during the 11th Asian Games in Beijing, China established the first professional car rental company--Beijing Jiulong Fusite Car Rental Co., Ltd. Later on, some car rental enterprises successively established in Shanghai, Tianjin, Guangzhou and other major cities, such as Shouqi Car Rental Co., Ltd. During initial period, the supporting facilities such as national macro industrial policy, industrial management and policy and laws had not been developed, resulting in the disorder and chaos of car rental market, high rental risk, and inability to protect legal interests.

\section{The second stage: regulation and rectification} period (1998-2004)

In order to solve the problems arose in the previous stage, the government began to rectify the market. The Ministry of Internal Trade, Ministry of Communications and the State Development Planning Commission successively issued the Notice on Carrying Out the Pilot Work of Car Rental and the Interim Provisions on the Management of Car rental Industry. So far, the traditional car rental model has been holding a monopoly position in the car rental industry for a long time. The power source of the traditional car rental mode is generally gasoline fuel. The exhaust gas and waste are the main causes of current air pollution. Therefore, how to realize the transformation of car rental industry is a question that the whole industry has been exploring.

3. The third stage: development pain period (2004-2014)

Due to the rapid development of social economy and a series of national policies, such as the encouragement policy for automobile consumption, purchase restriction and number restriction policies, and official business vehicle policy, the market demand for car rentals had exploded. As there was no unified regulation on the qualification, vehicle, personnel and management of car rental enterprises, the car rental industry had gone through a process from "governance" to "chaos". The Ministry of Transport issued Notice on Promoting the Healthy Development of Car Rental Industry on April 27, 2011, pointing out that it is necessary to establish and improve a legal car rental system, accelerate the formulation of a development plan for the car rental industry, guide the large-scale, networked and branded development, strengthen the management of car rental, innovate the car rental service mode, and intensify the supervision of car rental market. 


\section{The fourth stage: rapid development period} (2014 to now)

With the rapid development of domestic Internet, big data, cloud computing and other modern technologies, the car sharing mode emerged. From 2014 to now, the number of car sharing enterprises and cars has exploded. Different from the conventional fuel vehicles used in traditional car rental, the models in current car sharing are basically new energy electric vehicles. In July 2014, the State Council issued the Guiding Opinions on Accelerating the Promotion and Application of New Energy Vehicles, clearly stating that in order to effectively relieve the energy and environment pressure, it is necessary to accelerate the promotion and popularization of new energy vehicles, take pure electric vehicles as a major strategic orientation for the development of new energy vehicles, and speed up the innovation on car sharing and time sharing modes.

(II) Development trend of new energy vehicle sharing in China

1. With huge development potential in market, the new energy vehicle sharing is still a sunrise industry in China.

Compared with developed countries, the development level and service capacity of traditional car rental industry in China are still far behind. The number of rental vehicles and market scale in China are only $1 / 10$ and 1/5 of those in the United States respectively. As the economy and society of China develop rapidly, people's living standards have been improved significantly. Intra-city and urban-rural business trip, leisure tourism, commuting transport and other activities will become more and more frequent. In addition, driving skills are widely popularized, and the consumption concept of "not for all, but for use" is increasingly accepted by the public. New energy vehicle sharing has a broad development prospect.

2. New energy vehicles are mainly used in the time-sharing rental market, and the vehicle grades are generally not high.

Since the technical performance of new energy vehicles is difficult to meet the needs of traditional rental business, traditional rental enterprises rarely use new energy vehicles to carry out business. As the new energy vehicles are mainly used in time-sharing rental market, under the effect of national promotion and application policies for new energy vehicle, more than $95 \%$ of time-sharing rental vehicles are pure electric vehicles, and only a few rental enterprises such as Togo, Car2go and iCar use traditional fuel vehicles. Pand-Auto adopts battery exchange mode based on the technology of Lifan Group, its main investor, while other time-sharing rental new energy vehicles basically adopt charging mode. In terms of vehicle grade, except the mid-to-high end models such as BMW I3 and Roewe ERX5 used by a few enterprises like Gofun and Evcard, most other rental enterprises adopt low-end pure electric cars such as Chery and Baic in order to reduce operating costs, and the price is usually $50,000-100,000$ yuan after subsidy.

3. The background of car-sharing enterprises is related to automobile industry, and new energy related enterprises actively participate in it.
The background of most car-sharing enterprises is related to the car industry, and there are mainly five categories: the first category is the care-manufacturing enterprises, such as Evcard invested by SAIC Motor, Car2go and Car2share invested by Daimler-Benz AG, and Pand-Auto invested by Chongqing Lifan Group; the second category is the traditional rental enterprises, such as Gofun operated by Shou Qi Group, and iCar operated by China Auto Rental; the third category is the Internet platform enterprises, in which the Internet companies establish the platform and organize the vehicle operation, such as Baojia Rental, Togo, Ponycar, etc.; the fourth category is the vehicle battery production enterprises, such as Ibgoing Chuxing invested by the vehicle battery production enterprise Shenzhen Xingzhi Youdao Automobile Service Co., Ltd.; the fifth category is the charging pile enterprises, such as Eakay Chuxing, which is the new energy time-sharing rental platform for "integration of car + pile + parking space" comprehensive operation and management.

4. The car-sharing business model is forecasted with good market expectation, becoming a new investment hot spot in the field of travel.

In recent years, the car-sharing industry has developed rapidly in China. As of 2014, there were only a few companies (e.g., Zhejiang Microcity and Shandong MIT Limited) that introduced the foreign "car-sharing" operation mode into China and carried out the time-sharing rental business as pilot project. Various social capitals have also invested in the new energy car sharing industry. In February 2018, DiDi Chuxing reached a strategic cooperation with 12 car manufacturers including BAIC BJEV and BYD AUTO, planning to build a new energy car sharing project, with an estimated investment of 1 billion yuan in the future. In March 2018, Daimler-Benz AG and BMW issued a joint declaration to merge two wholly-owned time-sharing rental subsidiaries, i.e., Car2go and Drivenow, and said that they would expand the scale of time-sharing rental business. As the many major car manufacturers start to make market layout in the new energy car sharing industry, and as the social capitals start to pay attention to this industry, the new energy car sharing mode is gradually becoming a new investment hot spot.

5. Many local governments promulgate incentive policies to promote the deep integration of new energy car sharing mode with "Internet +".

In the incentive policies promulgated by the national and local governments related to the new energy vehicle rental industry, it puts forward a requirement clearly to encourage the active exploration of the new "Internet +" application model of new energy vehicles. Throughout the current market perspective, all the major new energy car sharing enterprises are based on Internet + Technology. The deep integration of mobile Internet, Internet of things, big data, artificial intelligence and other technologies into the new energy car sharing industry has brought the consumers an increasingly convenient car rental experience. Especially for the new energy car sharing enterprises represented by China Auto Rental, they have made continuous advancement in multiple innovative service modes including the 
scenario-based development, none-store operation and intelligent operation. The users can place an order and pick up the car anytime and anywhere, which has stimulated the market demand for new energy car sharing industry to a large extent.

\section{Problems of Car-sharing Development for New Energy Vehicles in China}

\section{The construction of policy and regulation system} lags behind.

There are no laws or regulations specifically stipulated against the car rental industry at national level up to now. A series of policies both at national and local levels related to the car-sharing industry of new energy vehicles are basically promulgated in 2017, which also indirectly reflects the fact that it is relatively late for the Chinese government began to attach importance to the time-sharing rental business of new energy vehicles. The relevant measures promulgated at national level are mainly focused on the policy of Guiding Opinions on Promoting the Healthy Development of Minibus Rental Industry in 2017. The policies promulgated at local level also exist in the first-tier cities, however, there still lack of government-related incentives in some new first-tier cities and second- and third-tier cities where the new energy car sharing enterprises are pouring into.

2. The parking space resources are in short supply, and the charging facilities are not well developed.

The car-sharing business mainly serves for urban travel, however, due to common shortage of urban parking space resources, especially in the core area of first- and second-tier cities, the parking spaces are difficult to obtain and the enterprises have to bear a high cost, as a result, the large-scale development and networked layout of the rental network are limited. For the use of new energy rental vehicles, since the urban charging facilities are not perfect yet, the users have to pick up and return the car at a fixed location in many cases, thus there is a poor experience in car rental convenience. The inconvenience of car rental and return leads to a low car rental rate and a low average single-car daily revenue, and the car rental pricing is generally low as the enterprises are in the market development stage, therefore, it is difficult to achieve the break-even point. Moreover, as the tidal phenomenon of urban travel is obvious, in order to meet the demand of using vehicles, the enterprises have to invest a large number of human resources and financial resources for vehicle deployment, thus further aggravating the difficulty in profits recover.

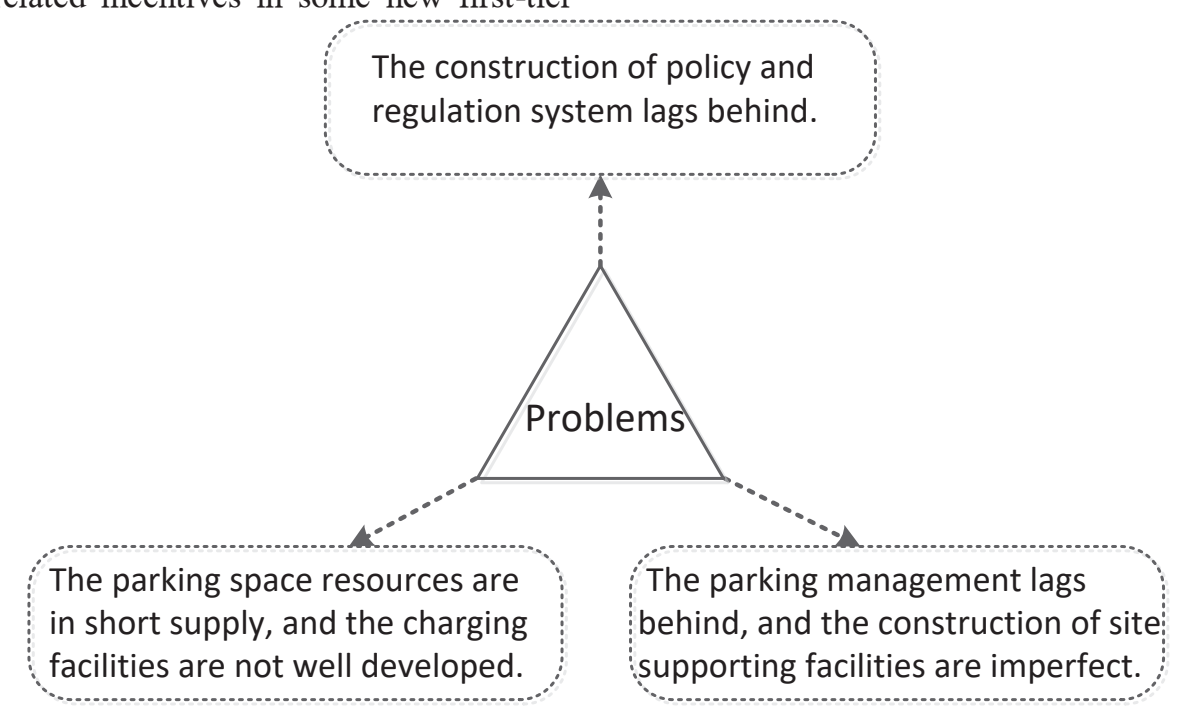

Figure 2. Problems of Car-sharing Development for New Energy Vehicles in China.

3. The parking management lags behind, and the construction of site supporting facilities are imperfect.

All major cities in China face the problem of imperfect parking management system. For example, many parking charging spaces are owned by the private contractors and are scattered disorderly; the parking facilities and equipment are poor and backward; the parking prices can not reflect the actual market demand; the laws and regulations system related to parking is not well-established. More importantly, there is not a special department in local governments responsible for parking management, and it is often hard to consult and communicate with the relevant departments on parking management issues in the cities where the car-sharing business is just getting started. Therefore, for the operators that carry out the new energy car sharing business in China, it is impossible for them to obtain preferential policy to use the public parking spaces. The operators can only set up their service sites on the private parking spaces, but such private parking spaces are usually far away from the main streets, thus it is difficult or inconvenient for the users to find.

\section{Policy Suggestions on Car-sharing Development of New Energy Vehicles in China}

1. Raise the awareness of Government and public, and incorporate it into the comprehensive transportation planning strategies.

The mode of transportation travel in China is 
currently in the stage of changing from single mode to composite mode. As a new mode of transportation travel, the government shall fully recognize the role of new energy car sharing mode in alleviating the urban traffic congestion, reducing the energy consumption, reducing the environmental pollution and strengthening the public transport attraction, and shall attach importance to the car-sharing development of new energy vehicles from the strategic height of modern urban development and central city function enhancement. The key success factor for developing and promoting the car-sharing service of new energy vehicles is to incorporate the car-sharing mode of new energy vehicles into the comprehensive transportation planning strategy, so as to make it an integral part of motor vehicles for the sustainable urban transportation network as well as a supplement to the public transportation system.

2. Encourage the car-sharing development of new energy vehicles, and accelerate the construction of public charging facilities.

The competent transportation department shall intensify the policy guidance on energy conservation and emission reduction, encourage the car-sharing enterprises to use the new energy-friendly vehicles, and speed up the popularization and application of new energy and hybrid power vehicles in car-sharing mode, encourage the development and application of new equipment and technologies that are conducive to energy conservation and emission reduction, study and establish the assessment system of energy conservation and consumption reduction for the car-sharing enterprises, and incorporate it into the annual quality credit assessment of car-sharing enterprises. The local government shall accelerate the promulgation of technical regulations on engineering design, construction, completion acceptance and operation \& maintenance of charging facilities, further standardize the construction and management of charging facilities, speed up the construction of charging facilities in the residence communities and unit parking lots, and encourage the qualified residence communities to increase their power capacity.

3. Fully advance the electrification of vehicles in the field of car sharing, and constantly enhance the capability of standardized service and intelligent transportation management.

The government shall fully advance the electrification of vehicles in the field of car sharing, encourage to adopt new energy vehicles as the new and updated vehicles in the field of car sharing, and guide the vehicle manufacturers to develop products with long mileage, fast charging speed and high reliability, in order to adapt to the demands of the car-sharing market, establish the sales, maintenance and repair network of new energy vehicles, constantly enhance the capability of standardized service and intelligent transportation management, and provide the professional services for all-round popularization and application of new energy vehicles. The competent transportation department shall strengthen the real-time monitoring and statistical analysis on the operation of new energy vehicles in car-sharing mode, collect the dynamic data of new energy vehicles from all aspects, and ensure the green travel of new energy vehicles to be safer and more convenient.

4. Actively expand the application range of "Internet + New Energy Car Sharing Mode", and build a comprehensive information service system for green travel

The government shall support the sharing mode development of new energy vehicles including time-sharing rental. The special parking spaces for new energy vehicle charging shall be opened in the transportation hubs such as airport and high-speed rail station as well as in the public parking lots of assembly occupancy such as centralized office area, colleges and universities, shopping malls, supermarkets, commercial buildings, residence communities, etc. The government shall foster the "Internet + New Energy Vehicle" service enterprises, support the enterprises to break through core technologies, and accelerate the process of industrialization, advance the development of convenient green transportation service based on the Internet platform, and build a perfect comprehensive information service system for public green travel, including Internet rental bicycle, new energy sharing car, new energy rental (or online car-hailing) car, new energy bus, etc.

5. Accelerate the cultivation of green travel industry chain of new energy vehicles, and improve the overall technical level of the industry

The government shall enhance the capability of R\&D, design, manufacturing and industrial integration for new energy vehicles, components and parts (batteries, motors, electrical controls), and improve the overall technical level of the industry, strengthen the construction and management of supporting services, including new energy vehicle inspection \& testing, remote monitoring, power battery recovery enterprises, automobile after-sales market, etc, vigorously develop the industry of new energy vehicles and fuel cell vehicles connected with intelligent network.

\section{Conclusion}

The emergence of new energy car sharing mode conforms to the general orientation of energy conservation and emission reduction, and blaze a new path for green travel. It is necessary to pack a punch from top to bottom in order to introduce a new way of using cars. With the promotion of policies, innovation of new energy vehicle enterprises and enhancement of public awareness on environmental protection, in the future, the new energy car sharing mode combining dual advantages of Internet and new energy vehicles will gain recognition and acceptance at both social and individual levels.

\section{References}

1. Yixiao Yin, Chaohui Zhong (2016) Green Travel: Road of Urban Transportation Development in China [J]. Science \& Technology Review, (17).

2. Tolley Rodney (British) (2013) Sustainable Transport: Urban Transport and Green Travel [M]. 
Machinery Industry Press, Beijing.

3. Qingping Guan (2016), Research on Innovation Model of Electric Vehicle Rental in Mobile Internet [D]. Donghua University.

4. Yue Xue, Tongyu Yang and Subin Wen (2008) Analysis on Development Model and Socio-economic Characteristics of Car-sharing Consumption [J]. Technoeconomics \& Management Research, (1):54-58.

5. Lanjun Xu (2017) Research on Business Model Innovation of Electric Vehicle Time-sharing Rental in China [D]. Beijing Jiaotong University.

6. Weiqun Han, et al. (2014) Research on Operation Model and Risk of New Energy Vehicle Rental [J]. Journal of Wuhan University of Technology, (01): $147-151+156$.

7. Lin Zou (2017) Government Planning Guidance Needed in New Energy Vehicle Rental Market [J]. Modern SOE Research, (07): 87.

8. Yingjun Qiao \& Xuehong Ji (2018) Development of Car-sharing Industry and Promotion of Automobile Power Construction [J]. Chinese Engineering Science, 20(1): 120-126.

9. Xiaodong Ruan (2017) New Business model of Sharing Economy: Car-sharing Growth Path [J]. New Economy Weekly, (9): 68-73. 